\title{
Debating Scientific Medicine: Homoeopathy and Allopathy in Late Nineteenth-century Medical Print in Bengal $^{1}$
}

\author{
SHINJINI DAS* \\ Centre for Research in Arts, Social Science and Humanities, University of Cambridge, \\ 7 West Road, Cambridge CB3 9DT, UK
}

\begin{abstract}
The historiography of medicine in South Asia often assumes the presence of preordained, homogenous, coherent and clearly-bound medical systems. They also tend to take the existence of a medical 'mainstream' for granted. This article argues that the idea of an 'orthodox', 'mainstream' named allopathy and one of its 'alternatives' homoeopathy were co-produced in Bengal. It emphasises the role of the supposed 'fringe', ie. homoeopathy, in identifying and organising the 'orthodoxy' of the time. The shared market for medicine and print provided a crucial platform where such binary identities such as 'homoeopaths' and 'allopaths' were constituted and reinforced. This article focuses on a range of polemical writings by physicians in the Bengali print market since the 1860s. Published mostly in late nineteenth-century popular medical journals, these concerned the nature, definition and scope of 'scientific' medicine. The article highlights these published disputes and critical correspondence among physicians as instrumental in simultaneously shaping the categories 'allopathy' and 'homoeopathy' in Bengali print. It unravels how contemporary understandings of race, culture and nationalism informed these medical discussions. It further explores the status of these medical contestations, often self-consciously termed 'debates', as an essential contemporary trope in discussing 'science' in the vernacular.
\end{abstract}

Keywords: Scientific Medicine, Debate, Vernacular, Medical Correspondence, Medical System, Orthodoxy

I regret to see in a late leading article... that you adopt the nickname 'allopathy', which the homoeopathists have tried to impose on the profession....2

[A] slight acquaintance with the controversial medical literature of the day shows that the members of the orthodox profession, although they may and do differ from each other in an almost every

* Email address for correspondence: das.shinjini@gmail.com

${ }^{1}$ I am indebted especially to Sanjoy Bhattacharya, Guy Attewell, Gautam Bhadra, Roger Cooter, Rohan Deb Roy, Lauren Kassell, Joya Chatterjee, Chris Pinney and the anonymous referees for their encouraging comments and critical suggestions.

2 J. Snow, 'On the Use of the Term "Allopathy”, To the Editor of the Lancet', Lancet, 47, 1173 (February 1846), 229. 
particular regarding the treatment of every disease, are singularly unanimous only in their denunciation of homoeopathy. ${ }^{3}$

This article focuses on a range of polemical writings by physicians in the Bengali print market since the 1860 s. Published mostly in late nineteenth-century popular medical journals, these concerned the nature and definition of 'scientific' medicine. The article highlights these published disputes and critical correspondence among physicians as instrumental in shaping the categories 'allopathy' and 'homoeopathy' in Bengali print. It further identifies these medical contestations, often self-consciously termed 'debates', as an essential contemporary trope in discussing 'science' in the vernacular.

Systematic self-projection by a growing body of Bengali authors as practitioners of homoeopathy initiated the said debates. These date back to the decade of the 1860s when the first Bengali private commercial firm Berigny and Company began its enduring investments in homoeopathic drugs and publications in Calcutta. ${ }^{4}$ Established by Rajendralal Dutta in 1866, Berigny and Company's Calcutta Homoeopathic Pharmacy was supposedly 'the first and the oldest' homoeopathic pharmacy in India. ${ }^{5}$ In the existing historiography of health and medicine in colonial India, the trajectory of homoeopathic therapeutic remains largely unaccounted for. This is sometimes attributed to the fact that homoeopathy did not quite fit into the 'frameworks grounded in sharp western/indigenous divide' deployed by historians in the study of medical ideas and practices in the colonial period. ${ }^{6}$ Indeed, historians of medicine in British India have remained overwhelmingly concerned with the myriad facets of state sponsored western medicine or with the 'indigenous' practices. The status of 'other' western medical ideas like homoeopathy that did not enjoy the support of the colonial state, yet developed deep roots in British India, await thorough historical investigation.

A few revealing articles have attempted to fill this historiographic void. Writing in the early 1980s, Surinder M. Bharadwaj and Donald Warren elaborated on the processes of homoeopathy's rapid 'indigenisation' owing to a 'natural' compatibility between homoeopathic principles and those of Ayurveda. ${ }^{7}$ In their recent work on homoeopathy's cultural appeal to the Bengalis, David Arnold and Sumit Sarkar discussed its modern, rational claims. They argued that while the state was invested in the propagation of colonial medicine, homoeopathy's professed German origin added to the cultural nationalist aspiration of the Bengalis. ${ }^{8}$ The cheapness and do-it-yourself appeal of homoeopathy also enhanced its appeal in the middle-class Bengali household. ${ }^{9}$ A few articles have assessed the role of the stalwart Bengali practitioner Mahendralal Sircar in the propagation

\footnotetext{
${ }^{3}$ Mahendralal Sircar, 'A Moribund Vindication of Rational Medicine', Calcutta Journal of Medicine, 7 (April-May 1874), 173.

${ }^{4}$ For details, see S.C. Ghosh, 'Dr T. Berigny', Hahnemann, 22, 4 (1939), 198.

5 Ibid.

${ }^{6}$ D. Arnold and S. Sarkar, 'In search of rational remedies: homoeopathy in nineteenth-century Bengal', in W. Ernst (ed.), Plural Medicine, Tradition and Modernity, 1800-2000 (London and New York: Routledge, 2002), 53-4.

7 S.M. Bharadwaj, 'Homoeopathy in India', in G.R. Gupta (ed.), The Social and Cultural Context of Medicine in India (New Delhi: Vikas, 1981), 31-54; see also Donald Warren, 'The Bengali Context', Bulletin of the Indian Institute of History of Medicine, 21 (1991), 17-51.

${ }^{8}$ Arnold and Sarkar, op. cit. (note 6), 41-54.

${ }^{9}$ Ibid., 41-54.
} 
of homoeopathy. ${ }^{10}$ Apart from these, Gary J. Hausman's illuminating article on mid twentieth-century south India reveals the flexibility of the notions of 'indigenous' and 'scientific' in the context of state recognition of homoeopathy. ${ }^{11}$

A common assumption in works on homoeopathy in South Asia is its conception as a monolithic, homogenous and clearly defined medical 'system' that travelled as such from Europe into India. Equally, they tend to presume the presence of a given, welldefined tradition of medical orthodoxy, termed 'allopathy' against which it registered and defined its place. These works take the connotations of the categories 'orthodoxy' and 'homoeopathy' for granted.

This article, instead, studies the constitution of these labelled identities. It argues that in the shared market for medicine and print in late nineteenth-century Bengal categories such as 'homoeopathy' and 'allopathy' were being simultaneously produced. In so doing, it speaks of histories that have illuminated us to the enabling role of so-called 'alternative', 'heterodox', 'sectarian' or 'fringe' medicine in the making of the medical 'mainstream', 'orthodoxy' or 'scientific medicine' in British and American contexts. ${ }^{12}$ Scholars have further hinted at the flexibility of terms such as 'orthodox', 'scientific' and 'alternative' when studied over a period of time in these contexts. ${ }^{13}$ Drawing upon these insights, this article studies how a range of correspondence among competing physicians shaped understandings of contending medical traditions and systems - of 'allopathy' and 'homoeopathy' in Bengal. It unravels how contemporary understandings of race, culture and nationalism informed these medical discussions in vernacular print. It elaborates on the ways in which specific connotations of the categories 'allopathy' and 'homoeopathy' emerged in Bengali print. The article further adds to the recent historiographic interrogations around the makings of medical 'systems'. In tracing one of the many sites constituting 'homoeopathy' and 'allopathy' in Bengal, it commits to explore the processes through which a "seemingly clearly bounded "tradition" or "medical system" comes into existence' at any given context. ${ }^{14}$ In the process, this article also examines the ways in which the debates, initiated by homoeopathic self-assertions in Bengali print, engendered understandings of 'allopathy' as the acceptable name for a western orthodox tradition dating back to the days of Hippocrates. This becomes all the more evident from

${ }^{10}$ Chittabrata Palit, 'Dr Mahendrala Sircar and Homoeopathy', Indian Journal of History of Science, 33, 4 (1998), 289-92; Dhrub Kumar Singh, 'Choleraic Times and Mahendra Lal Sarkar: The Quest of Homoeopathy as "Cultivation of Science" in Nineteenth Century India', Medizin, Gesellschaft und Geschichte, 24 (2005) $207-42$.

${ }^{11}$ Gary J. Hausman, 'Making Medicine Indigenous: Homoeopathy in South India', Social History of Medicine, 15, 2 (2002), 303-22.

12 J.H. Warner, 'Orthodoxy and otherness: homeopathy and regular medicine in nineteenth-century America', in R. Jütte, G. Risse and J. Woodward (eds), Culture, Knowledge, Healing: Historical Perspectives of Homoeopathic Medicine in Europe and North America (Sheffield: European Association for the History of Medicine, 1998), 5-30; see also N. Rogers, 'American homoeopathy confronts scientific medicine', in R. Jütte, G. Risse and J. Woodward (eds), ibid., 46-7; R. Cooter (ed.), Studies in the History of Alternative Medicine (New York: St Martin's Press, 1988), xii-xviii.

${ }^{13}$ Robert Jutte, 'The Historiography of Non-Conventional Medicine in Germany: A Concise Overview', Medical History, 43 (1999), 342-3; see also D.G. Bates, 'Why Not Call Modern Medicine "Alternative"?', Perspectives in Biology and Medicine, 43, 4 (2000), 502-18.

${ }^{14}$ W. Ernst (ed.), Plural Medicine, Tradition and Modernity, 1800-2000 (London and New York: Routledge, 2002), 7. For recent works that look into the making of indigenous medical systems of India, see Guy Attewell, Refiguring Unani Tibb: Plural Healing in Late Colonial India (New Delhi: Orient Longman, 2007), 1-49. For a anthropological work on contemporary Ayurveda, see Jean Langford, Fluent Bodies: Ayurvedic Remedies for Postcolonial Imbalance (Durham: Duke University Press, 2002). 
the fact that systematic assertions of medical 'orthodoxy' remained singularly lacking in official as well as popular publications prior to the decade of the 1860s.

Indeed, successive colonial administrations throughout the nineteenth century did not clearly circumscribe the kinds of medical practice that could be taught or practiced in Bengal. British officials were far from naming any particular medical tradition or system as part of their conscious agenda to propagate. The term 'allopathy' hardly ever featured in the initial state bureaucratic correspondence or in the early nineteenth-century medical literature. Even the Calcutta Medical College established in 1835, under direct state patronage, made a general commitment of teaching medicine 'on European principles and through the medium of the English language' ${ }^{15}$ Existing works have noted the central role played by the Calcutta Medical College in the colonial medical interventions in Bengal. ${ }^{16}$ Medicine taught at this state-run institution and others were known by different labels. At various moments, it came to be referred to as 'Official medicine', 'Rational medicine', 'Western medicine', 'English medicine' or simply as the 'Medical Profession' by the graduates of the college and by officials attached to the medical establishment of the state. This article traces the emergence and circulation of the term 'allopathy' in late nineteenthcentury popular print. It studies the process in which the term 'allopathy' replaced these various terminologies and emerged as the accepted and most frequently used name of a supposedly orthodox and mainstream western medical tradition in Bengal. It further argues that the quintessential features of western orthodoxy also came to be crystallised through such correspondence.

As indicated at the beginning, a study of the debates entails an exploration of the selfassertion of physicians claiming to popularise homoeopathy in vernacular print. Since the late 1860 s with the gradual establishment of various private commercial firms dealing in homoeopathic drugs and print, there was an increased spate of publications promoting homoeopathy. ${ }^{17}$ A number of physicians claiming to practice homoeopathy asserted the superior scientific merit of their therapeutics in journals, manuals and pamphlets targeted at a generalised audience. Existing historical works reveal that Bengal witnessed a tremendous proliferation of printing presses by the mid-nineteenth century. ${ }^{18}$ Recent works have shown that medical literature of different kinds formed a significant bulk of these vernacular publications. ${ }^{19}$

A range of homoeopathic pamphlets, manuals, monographs and materia medica were published after the late 1860s. In most of these texts, the authors made a concerted effort to project the advanced and scientific status of homoeopathy. A few manuals were published serially over an extended period such as Datta's Homoeopathic Series (1875-8) or Berigny

\footnotetext{
${ }^{15}$ Late Principle Bramley's Report: Report of the General Committee of Public Instruction of the Presidency of Fort William in Bengal for the Year 1836 (Calcutta: Baptist Mission Press, 1837), 32-3.

16 David Arnold, Science, Technology and Medicine in Colonial India: New Cambridge History of India III: 5 (Cambridge: Cambridge University Press, 2004), 64-5.

${ }^{17}$ A number of family firms began investing in homoeopathic drugs and print since that time. For a greater exploration of the activities of these firms and the popularisation of homoeopathy in Bengal see 'Homoeopathic Families, Hindu Nation and the Legislating State: Making of a Vernacular Science, Bengal 1866-1941' (unpublished PhD thesis: University College London, 2012).

${ }^{18}$ T. Ray, 'Disciplining the printed text: colonial and nationalist surveillance of Bengali literature', in P. Chatterjee (ed.), Texts of Power: Emerging Disciplines in Colonial Bengal (Minneapolis: University of Minnesota Press, 1995), 34-62; see also Anindita Ghosh, Power in Print: Popular Publishing and the Politics of Language and Culture in a Colonial Society, 1778-1905 (Delhi: Oxford University Press, 2006).

${ }^{19}$ Projit Bihari Mukharji, Nationalizing the Body: The Medical Market, Print and Daktari Medicine (London and New York: Anthem Press, 2009), 75-110.
} 
and Company's Bengali Homoeopathic series (1870-6). ${ }^{20}$ More usually, however, the genre of popular medical journals dedicated broadly to health and medicine, provided a forum for discussing contrasting medical ideas and traditions. Some example of these were Chikitsha Sammilani [Assemblage of Treatment], Chikitshak O Samalochak [Physician and the Critic], Chikitshak [Physician], Bigyan Darpan [Mirror of Science], Swasthya [Health], etc. Physicians advocating homoeopathy made extensive use of these journals in asserting homoeopathy's superior scientific status. Exclusively, homoeopathic journals such as the Calcutta Journal of Medicine, Hahnemann or the Indian Homoeopathic Review remained most devoted to the dissemination of these ideas.

However, self-projection of the homoeopaths in these forums did not take place on its own. It extensively engaged with the already prevalent medical ideas of European origin. Medicine practiced by the graduates of the government Medical College came to be insistently referred to and denounced as 'orthodox', 'old school' or 'allopathic' medicine by them. Through their repeated ascription of the terms 'orthodox' or 'allopath' to medics associated with government Medical College, the homoeopaths introduced and reinforced these labels in the medical literature of the time.

These homoeopathic self-assertions as superior medical knowledge hardly went unnoticed. Many physicians responded by objecting to them, resulting in the publication of enduring discussions concerning the precise connotation of 'scientific' therapy. ${ }^{21}$ Physicians educated at the state backed institutions internalised these labels while answering back. They responded to homoeopathic attacks as practitioners of western 'orthodox' medicine or 'allopathy' in the pages of these journals. They strongly upheld their identities as practitioners of a long standing and well-formulated tradition that went by the name 'allopathy'. In their response to the homoeopathic criticisms, the distinguishing features of medical 'orthodoxy' were elaborately discussed and delineated. The terms 'orthodoxy' and 'allopathy' were invoked and used interchangeably in the discussions.

These late nineteenth-century polemical discussions among physicians concerning 'scientific' therapeutics often assumed an aggressive tone. The thread run by 'allopathic' practitioner Pulin Chandra Sanyal and 'homoeopath' Haranath Ray in the journal Chikitsha Sammilani is typical. The conversation between this particular pair of physicians ran into several volumes of Chikitsha Sammilani beginning in the fourth volume of the journal in 1887. The debate took off with Haranath Ray's article titled 'Homoeopathic Mowt e Jvar Chikitsha [Homoeopathic treatment of fever]'. ${ }^{22}$ Pulin Chandra Sanyal wrote a stern reply attacking the very fundamentals of so-called homoeopathic medicine. ${ }^{23}$

Disagreements between the 'allopathic' and 'homoeopathic' physicians were founded on the scientific merit of their respective therapeutics. Indeed, in discussing medical practices, the debates simultaneously attempted to chart out the definition and scope of 'science'. Hence, what qualified as 'science' fundamentally preoccupied the participants.

\footnotetext{
${ }^{20}$ A series of homoeopathic manuals published by Berigny and Company entitled Sadrisa Byabostha Chikitsha Dipika came out from the 1870s. The series contained several homoeopathic manuals written by Harikrishna Mallika. Each issue dealt with the homoeopathic cure of different diseases. Likewise, Datta's Homoeopathic series edited by Basanta Kumar Datta was published in Calcutta from 1876.

${ }^{21}$ Liebeskind studied a similar debate concerning scientific medicine between the hakims and practitioners of 'western' medicine in a slightly later period: C. Liebeskind, 'Arguing science: unani tibb, hakims and biomedicine in India, 1900-1950', in W. Ernst (ed.), Plural Medicine, Tradition and Modernity, 1800-2000 (London and New York: Routledge, 2002), 58-75.

${ }^{22}$ Haranath Ray, 'Homoeopathic Mowt e Jvar Chikitsha', Chikitsha Sammilani, 4 (1887), 122-6.

23 Pulin Chandra Sanyal, 'Ini Abar Ki Bolen', Chikitsha Sammilani, 4 (1887), 304-8.
} 
Existing historiography notes an unprecedented contemporary interest in science in both popular as well as professional/specialised circuits. ${ }^{24}$ They have elaborated on the ways in which science served as a domain of assertion of nationalism against the colonial regime. It is possible to situate these fiery medical correspondences regarding the scientific merit of opposed medical ideas in this broader social ambience. The discussions centred on different issues relating to scientific therapeutics. The first four sections study the contestations around issues such as the necessity of a universal therapeutic law in treatment, the ideal methodology to be adopted in proper scientific treatment and also the kind and dosage of drugs that ought to be dispensed. The fifth section demonstrates how the history of each medical tradition and their antiquity also constituted a significant aspect of contention. These five sections examine the processes through which issues concerning law, methodology, drugs and history were framed in relation to assertion of medical authority and respectability. The final section studies the Bengali glorification of debate as a necessary and exalted practice in discussing science. It further traces the various features of an 'authentic' scientific debate that emerged from the nineteenth-century vernacular discussions.

\section{Of 'Absolute and Universal Laws' ${ }^{25}$}

The essential scientific claim of homoeopathy lay in the discovery of a universal law of medicine. Hahnemann, commonly regarded as the father of homoeopathy, 'discovered' the law 'Similia Similibus Curentur' meaning 'like cures like' in $1790{ }^{26}$ Widely known as the 'law of similars', this law was highlighted as the fundamental truth of homoeopathy. According to it, medicine that was to be administered for the cure of any disease should be the one capable of producing a similar set of symptoms in a healthy person. Thus, a medicine given for cholera should be able to produce symptoms like cholera if administered to a person in health. The law, acknowledged as the most reliable and universal guide to therapeutics, was celebrated as 'the very corner-stone of homoeopathy, it has been and ever will be the law of all therapeutic power' ${ }^{27}$

Mid nineteenth-century medical literature in Bengal is replete with discussions around the desirability of a fixed definite therapeutic law. Physicians frequently highlighted it as the hallmark of respectable science. However, physicians claiming to practice orthodox medicine critiqued the homoeopathic claim of having already discovered a universal therapeutic law. Writing in the Indian Medical Gazette in 1878, the semi-official Calcuttabased organ of the colonial state, one of them commented:

The laws of drug-action will eventually depend upon exact researches, but the process is necessarily a slow one.... Meantime men in the ardent thirst for finality and unification will not wait.... This has arisen a crop of theories regarding drug action, which pretend to formulate absolute and universal laws... like Homoeopathy. .. these pathies are the false gods of medical science.... ${ }^{28}$

\footnotetext{
${ }^{24}$ See, for instance, Pratik Chakraborty, 'Science, Morality and Nationalism: The Multifaceted Project of Mahendra Lal Sircar', Studies in History, 17, 2 (2001), 245-7.

25 Anonymous, 'Therapeutical Laws', Indian Medical Gazette, 13 (August 1878), 216.

${ }^{26}$ Contemporary homoeopathic texts in Bengal extensively highlighted the process of discovery of the law by Hahnemann. For instance, see F.C. Skipwith, 'Homoeopathy, and Its Introduction in India', Calcutta Review, 17 (1852), 22.

${ }^{27}$ Quoted in W. Robson, Homoeopathy Expounded and Exposed, A Lecture Delivered in the Theatre of the Medical College, Calcutta, March 20th, 1867 (Calcutta: Wyman Bros, 1867), 5.

28 Anonymous, op. cit. (note 25), 216.
} 
The law thus constituted a central fulcrum around which medics contested each other's claim to scientificity. Physicians claiming to practice orthodox medicine questioned the validity and the universality of the law. Through their writings, they often discussed the absurdity of such a law. Another article in the Indian Medical Gazette argued:

The uncertainties and imperfections of medicine are undoubtedly so many and so great that much latitude of opinion and practice must exist but they are not to be overcome by a blind subjection to a spurious 'law' which supplies a pretence of delusive finality. ${ }^{29}$

Physicians advocating homoeopathy countered these assertions with the accusation that 'allopathy' was unscientific. The author of the monograph Susrut and Hahnemann elaborated on the shortcomings of traditions that failed to provide a universal law for physicians. He held that '... devoid of any fixed law, theory or principle, orthodoxy can hardly claim itself to be scientific in orientation'.30

Those embracing the label of 'allopaths' were unanimous in their negation of an overarching and universal therapeutic law. Referring to unfounded homoeopathic allegations, physician Pulin Chandra Sanyal wrote in Chikitsha Sammilani, 'allopathy does not consist of any one law. It is a misconception to think that scientific knowledge necessarily has to be based on one fixed law or theory. Allopathy is based on not one, but several theories' ${ }^{31}$

\section{'Experimental Drug Proving' vs 'Galenic Hypothesis'}

The second contested issue involved the question of methodology. Physicians promoting homoeopathy projected it to be an experimental science thriving on empirical evidence. Their self-projections were often based on an attack on rationalism as a mode of acquiring credible knowledge. In successive homoeopathic texts in Bengali, 'allopathy' revealed itself as a genre that represented the inadequacies inherent in rational sciences. In contrast, the relative advantage of homoeopathy over what it designated as 'allopathy' was one of empirical and experimental rigor over rational deductions. Experimental 'drug proving' on a healthy human body was extensively highlighted as an essential feature of scientific therapeutics. ${ }^{32}$ The homoeopaths made a strong case for empiricism as opposed to the 'rational hypothesis of the Old School'. They contended that orthodox medicine was based on mere deductions as opposed to the careful inductive methodology adopted by them. In discussing Hahnemann's ideas an author in the homoeopathic journal Calcutta Journal of Medicine argued:

[T] he second rock upon which have come to break all the efforts to constitute therapeutics, is the spirit of hypothesis. It is the 'evil genius of medicine'... [Hahnemann] proposes experimentation. [He] Says, what I demand of you, young gentlemen, is not to become homoeopaths upon my word, but that you should attach yourself strongly to the experimental method which we present to your mind, and not tolerate when the teachers who, still pretending to be positivists, speak to you in the superannuated language of Galenic hypothesis. ${ }^{33}$

\footnotetext{
${ }^{29}$ Anonymous, 'Homoeopathy in the University of Calcutta', Indian Medical Gazette, 13 (June 1878), 159.

${ }^{30}$ Surendra Mohan Ghosh, Susrut o Hyaniman (Calcutta: Bengal Medical Library, 1906), 38-9.

${ }^{31}$ Pulin Chandra Sanyal, 'Uttore Pratyuttor', Chikitsha Sammilani, 5 (1888), 221.

32 Pratap Chandra Majumdar, 'Advertisement to the sixth edition', Oushadh Guna Sangraha, Sixth edn enlarged (Calcutta: 1911), page number not cited.

${ }^{33}$ Mahendralal Sircar, 'Reform of Hahnemann as the Basis of Positive Therapeutics, Public Conference upon Homoeopathy 1', Calcutta Journal of Medicine, 1, 1 (January 1868), 17.
} 
In his book Homoeopathic Chikitsha Bigyan [Homoeopathic Medical Science] physician Biharilal Bhaduri argued that physicians before Hahnemann used to select drugs by trial and error on a diseased patient. ${ }^{34} \mathrm{He}$ held that 'drug proving' or conducting drug tests according to stipulated rules on healthy human bodies was a phenomenon that distinguished homoeopathy from the prevalent orthodox practices. These laterday homoeopaths claimed to build upon Hahnemann's original Materia Medica Pura designed with the help of experiments he conducted. Bengali physicians advocating homoeopathy recounted Hahnemann's experiments with different drugs. ${ }^{35}$ The materia medicas published in Bengali likewise advertised themselves to be the results of extensive experiments by experienced physicians. ${ }^{36}$ In a famous speech, given at the annual meeting of the Bengal branch of the British Medical Association to mark his 'conversion' to homoeopathy, Mahendralal Sircar, the most eminent Bengali homoeopath, also highlighted this aspect. In the published pamphlet that resulted out of the speech he wrote extensively about the experiments with drugs he carried out on himself. Sircar argued:

.... I made trial of drugs myself - preparations with my own hands - they acted marvellously in removing diseased conditions .... I made trials of other remedies such as Aconite, Belladonna, Nux Vomica.... I must say that I observed their unmistakable influence over disease, when administered after the principle of similarity of symptoms. ${ }^{37}$

The homoeopathic physicians in Bengal were especially in favour of experimenting with various 'native' drugs. This was a topic of recurrent discussion in the pages of the foremost homoeopathic journal, Calcutta Journal of Medicine edited by Mahendralal Sircar.

Physicians claiming to practice orthodox medicine, completely disapproved of these claims of being experimental and a superior science. They ridiculed the idea of a homoeopathic drug proving on healthy bodies to determine the exact drug for each individual patient. In particular, the prescribed procedure of recording various minute symptoms generated by different substances in the body evoked much criticism. An article in the Quarterly Journal of the Calcutta Medical and Physical Society noted thus:

[I]n the materia medica of Hahnemann, even in the French translations by Jourdan, - no less than 46 octavo pages are devoted to the detail of the symptoms produced by charcoal in doses not exceeding the millionth of a grain. 720 is the number of symptoms ascribed to this dose of vegetable charcoal (carbo ligni) while 190 are attributed to the same quantity of carbo animalis. In other words, the $1 / 5,760,000,000$ of a dose which has been found to be perfectly inert is described as producing 720 symptoms. ${ }^{38}$

Despite strong criticisms, homoeopathic texts continued to emphasise the principle of empiricism and inductive methodology. Homoeopathy was widely advertised as the 'medicine of experience'. What constituted rational scientific therapeutics was a deeply contested topic among practitioners of the time. Proponents of homoeopathy argued that it was the only rational practice since it relied on solid empirical knowledge. Leopold Salzer, a Viennese practitioner of homoeopathy in Calcutta in the late nineteenth-century,

\footnotetext{
${ }^{34}$ B. Bhaduri (ed.), 'Preface', in Homoeopathic Chikitsha Bigyan (Calcutta: Saraswat Jontro, 1874), page number not cited.

${ }^{35}$ Mahendralal Sircar, 'Hahnemann and His Work', Calcutta Journal of Medicine, 12, 10 (May 1887), 401-2.

${ }^{36}$ Hariprasad Chakrabarty, 'Shikharthidig er proti upodesh or advice to the students', Homoeopathic Bhaishajya Tattwa (Calcutta: Chikitsha Tattwa Jontro, 1880), page number not cited.

${ }^{37}$ Mahendralal Sircar, On the Supposed Uncertainty in Medical Science and on the Relation between Diseases and their Remedial Agent (Calcutta: Anglo Sanskrit Press, 1867), 30-1.

38 Anonymous, 'Homeopathy Sketched in its Own Colours', Quarterly Journal of the Calcutta Medical and Physical Societies, 3 (July 1837), 411-12.
} 
developed this point in his 1871 monograph Rational Practice of Medicine. Arguing in favour of empiricism and experience as the most reliable mode of generating knowledge he asserted:

[W] are to be rescued from our theoretical and practical difficulties by means of Experience. The facts and principles of therapeutics we are told are obtained by experience. ... It is by the method of induction, that is by inferring from a number of facts relating to the same class of phenomena, a special truth or proposition which embrace them all, that we here proceed in the formation of our principles.... ${ }^{39}$

Physicians advocating homoeopathy critiqued orthodox medicine saying it relied unconditionally and exclusively on reason. Reason alone, without the help of direct experience and experiments, was considered an inappropriate methodology to attain scientific truths. Salzer further contended:

It should always be borne in mind that it is reason itself which raises its warning voice against its own trustworthiness in matters of experience; that it is reason which urges us to go elsewhere (namely to experience) for accurate enquiry. ${ }^{40}$

Principles of induction and empiricism were extensively criticised by those who stood up to defend 'orthodoxy'. In response to Mahendralal Sircar's 1867 treatise on homoeopathy, missionary Robson delivered a speech at the Calcutta Medical College which later got published. In that provocative pamphlet titled Homoeopathy Expounded and Exposed, allopath W. Robson confronted the homoeopathic reliance on inductive methods. ${ }^{41} \mathrm{He}$ contended that 'Homoeopathic reasoning from particular facts to general conclusions may fitly be described in the words of an old author who said, "they see a little way, suppose a great deal and then jump to the conclusion". ${ }^{42}$

As noted before, the characteristics of authentic 'science' were a topic of recurrent discussion in contemporary journals. We have referred to the long thread in the journal Chikitsha Sammilani between an allopathic physician Pulin Chandra Sanyal and homoeopathic physician Haranath Ray. Several other physicians contributed to their correspondence over the months. One such anonymous 'homoeopathic practitioner' elaborated on the two fundamental requirements of any science. According to him, credible scientific truths were results of extensive experiments and were necessarily based on infallible universal laws. He held that since homoeopathy possessed both, it alone qualified as a scientific therapeutic. To him, "Allopathy” was far from being a science as it lacked in the two basic features of nineteenth-century science'. ${ }^{43}$

\section{Gentle Drugs for a Debilitated Race}

The crystallisation of the idea of two opposed systems of medicine further involved discussions on the nature of the drugs dispensed by physicians. Such discussions, as this section would illustrate, were fraught with issues of race and nationalism. Advocates of homoeopathy argued that the 'heroic' therapy of orthodox medicine was the major impetus behind Hahnemann's discovery of the homoeopathic law in the late eighteenth century.

\footnotetext{
${ }^{39}$ Leopold Salzer, Rational Practice of Medicine, A Lecture Delivered at the School of Arts, Jeypore (Calcutta: Thacker and Spink, 1871), 9-10.

${ }^{40}$ Ibid., 412-13.

${ }^{41}$ W. Robson, Homoeopathy Expounded and Exposed, A Lecture Delivered in the Theatre of the Medical College, Calcutta, March 20th, 1867 (Calcutta: Wyman Bros, 1867), 13-14. This speech by Dr Robson was delivered in direct response to Mahendralal Sircar's conversion speech.

42 Ibid., 13-14.

43 Anonymous, 'Letter to the Editor by an Anonymous Homoeopath', Chikitsha Sammilani, 5 (1888), 105.
} 
To them, the novelty of homoeopathic remedies ever since depended on their supposed gentleness. Mid nineteenth-century medical writings in Bengal reveal a strong tension between physicians relating to the nature of the drugs they prescribed.

Physicians arguing in favour of homoeopathy projected their cure to be extremely gentle and mild on the body. They recurrently advertised the merit of their drugs as opposed to those prescribed by the orthodox medics. They argued that allopathic remedies generated harmful side effects on the body. ${ }^{44}$ Issues of race and class were frequently invoked to justify the use of homoeopathic drugs in India. Homoeopathy was advertised to be especially suitable for Indians in view of the mild nature of the drugs. Existing histories reveal how the colonial discourse on Indians had produced the stereotype of the weak Indian body. The image of the effeminate and weak Bengali babu has received special historical attention. ${ }^{45}$ The preferences shown towards homoeopathy reveal the various ways in which the colonial stereotypes were interiorised and reinforced by sections of the Bengali literates. Hariprasad Chakraborty, the author of a popular homoeopathic materia medica Homoeopathic Bhaisajya Tattwa [Homoeopathic Materia Medica] thus stated in the introduction of his book:

[T]he people of this country are becoming increasingly debilitated by the day. It is inadvisable for them to consume the strong allopathic drugs of high potencies. The milder homoeopathic drugs are much better suited to their needs. Besides, for domestic treatments, especially for the children as also for the poor hardworking people, homoeopathy is much better suited. ${ }^{46}$

In an article on homoeopathic treatment of fever, another homoeopathic physician discussed the unsuitability of 'allopathic' drugs on Indian bodies. It was pointed out that:

$[\mathrm{H}]$ igh doses of allopathic drugs reduce the pulse of the patient so much that often he fails to revive. This is only understandable. It is impossible for rice-eating Indians to consume the drugs that the cow-eating Europeans can digest. ${ }^{47}$

In view of this, the homoeopaths criticised the frequent use of mercury and quinine by 'allopathic' physicians. Mercury and especially quinine had earned the reputation of being two chief drugs used by the medics in the Calcutta Medical College. Homoeopathic practitioners argued that extensive use of the two drugs was dangerous since they produced various different diseases in the body. Many homoeopathic manuals even prescribed remedies for the probable symptoms contracted by the excessive consumption of 'allopathic' drugs like quinine and mercury. ${ }^{48}$

With the colonial medical establishment's major investments in the production and distribution of quinine in India, the latter provided an obvious site for contention. In various monographs as well as in a number of articles in medical journals the homoeopaths consistently argued against the usefulness of quinine in treating fever. It was argued that 'allopathic' prescription of generous doses of quinine turned the patients into 'patients-

\footnotetext{
${ }^{44}$ Harikrishna Mallika, 'Introduction', in Sadrisa Byabostha Chikitsha Dipika: Homoeopathic Treatment of Sexually Transmitted and Other Related Diseases, Berigny and Company's Bengali Homeopathic Series No. IV (Serampore: Alfred Press, 1870), page numbers not cited.

45 See, for instance, Indira Chowdhury, The Frail Hero and Virile History: Gender and the Politics of Culture in Colonial Bengal (New York: Oxford University Press, 1998); Mrinalini Sinha, Colonial Masculinity: the 'Manly Englishman' and the 'Effeminate Bengali' in the Late Nineteenth Century (Manchester: Manchester University Press, 1995).

${ }^{46}$ Chakraborty, op. cit. (note 36), page numbers not cited.

${ }^{47}$ Ray, op. cit. (note 22), 123.

${ }^{48}$ Harikrishna Mallika, Sadrisa Byabostha Chikitsha Dipika, Berigny and Company's Bengali Homoeopathic Series No. I (Calcutta: Alfred Press, 1870), 191-3.
} 
for-life'. Homoeopath Haranath Ray reminisced in an article in Chikitsha Sammilani of a malarial epidemic in Burdwan district where quinine was extensively distributed by the government. He remembered that 'the people, who initially benefited out of quinine, ended up suffering from enlarged spleens and livers.... Most of them eventually died'. ${ }^{49}$

Discussions in defence of homoeopathy frequently acquired distinct anti-colonial resonances. In the world of vernacular publications, allopathy was frequently perceived to be synonymous with the colonial medical establishment. Hence, in opposing allopathy there was an underlying implicit hint of opposing the power of the state. However, the modality of this opposition remained rather interesting. Proponents of homoeopathy refrained from adopting an explicitly Hindu revivalist tone. ${ }^{50}$ They made a case for countering the colonial medical interventions with a different variant of western medicine itself. Yet, issues of racial difference remained central in these discussions around homoeopathic drugs.

Self-proclaimed Bengali allopaths, however, valiantly defended quinine. Several explanations were put forward to justify the disease and the suffering of the native population. For instance, climates of certain localities were frequently highlighted as facilitating the spread of fevers. The inhospitable, disease-prone climate of the tropic was the another significant colonial stereotype propagated primarily through the official discourse on India. ${ }^{51}$ The reactions of the Indian physicians opposing homoeopathy reveal the agency of the Indians in circulating them. Orthodox physicians firmly held that largescale consumption of quinine provided the only respite from death in places where they were administered. In his article in Chikitsha Sammilani physician Pulin Chandra Sanyal, for instance, insisted that the locality of Ranaghat in 1882-3 suffered from malaria owing to the climatic orientation of the place. ${ }^{52}$ To him, far from being the cause of the plight of the people there, quinine was the only available drug that successfully controlled the disease in the region.

\section{Debating the Doses}

Discussions on the nature of the drugs were integrally related to those concerning the issue of dosage. It was repeatedly pointed out that Hahnemann had upheld the efficacy of the smallest possible dose of any drug. Homoeopathic publications in Bengal popularised this concept as 'sukkho matra' or the 'infinitesimal dose' of homoeopathy. Extremely minute doses were considered more powerful and efficacious than the 'large and heroic' doses prescribed by the 'orthodox' physicians. Many physicians considered it the most outstanding discovery of Hahnemann. In his conversion speech, Mahendralal Sircar held, '... this was his (Hahnemann's) real and most original discovery, one of the greatest that was ever made, and one which shall in future ages, be identified with his name' ${ }^{53}$

Physicians opposing homoeopathy launched the staunchest critique against the prescription of minute doses. They argued that the minute doses advocated by

\footnotetext{
${ }^{49}$ Ray, op. cit. (note 22), 125.

50 There have been historical works depicting the nationalist appropriation of the Ayurveda as the authentic Hindu medical tradition. For a case study of Punjab, see Kavita Sivaramakrishnan, Old Potions, New Bottles: Recasting Indigenous Medicine in Colonial Punjab 1850-194 (Hedrabad: Orient Longman, 2006). Her book deals extensively with Hindu reformist politics and its relation with Ayurveda.

${ }^{51}$ See, for instance, Mark Harrison, Climates \& Constitutions: Health, Race, Environment and British Imperialism in India, 1600-1850 (Oxford: Oxford University Press, 1999).

52 Pulin Chandra Sanyal, 'Ini Abar Ki Bolen', Chikitsha Sammilani, 4 (1887), 307.

${ }^{53}$ Sircar, op. cit. (note 37), 1-37.
} 
homoeopaths denied the logic of mathematics. In their writings, they repeatedly questioned the medicinal value inherent in the homoeopathic doses. An article in the Quarterly Journal of the Calcutta Medical and Physical Society thus noted sarcastically:

[T] he homoeopathic doctors never administer so much as a grain, for example, of any medicine, they go to work with the millionth, or fraction of a millionth, of that quantity, which no doubt is a potent recommendation of them to many people who hate the taste of drugs. But we apprehend that the world is not sufficiently aware of the miraculous effects of these invisible doses, which indeed seem to be the more wonder working the more infinitesimal and spiritual they are rendered. ${ }^{54}$

These physicians argued that most of the cures attributed to homoeopathic medicine in reality were results of other factors ranging from diet, to the healing power of nature. In his pamphlet physician Robson, for instance, was willing to admit:

[T] he facts of recovery but deny the homoeopathic or popular explanation, that this was owing in any way to the billionth of a grain of charcoal or sulphur... The recoveries were due entirely to the curative powers of nature and the strict dietetic regimen usually enforced. ${ }^{55}$

Contesting the scientific claims of homoeopathy, some of these texts drew analogy between homoeopathy and instances of faith healing. It was pointed out that:

The factor of faith is also important... all natives of India are familiar with the popular mode of treating serpent bites with mantras. Many of those so bitten recover under this treatment. Shall we here ascribe the recovery to the curative power of nature or call it a wonderful cure of incontrovertibly proving the medicinal power of the charm? A muttered charm is surely as likely a means of cure as smelling a homoeopathic globule. ${ }^{56}$

Indeed, the issue of faith was evoked time and again. In his pamphlet Robson further compared the cases of recovery with homoeopathic doses with those at the popular Hindu pilgrimage site of Tarakeswar. ${ }^{57}$

Physicians critiquing homoeopathy were evidently determined to prove the absence of any therapeutic value in homoeopathic infinitesimals. Amusing stories circulated in the pages of many prominent journals. A news snippet entitled 'Homoeopathic Pies' in the Indian Medical Gazette read as follows:

A year or more ago, the auctioneer had for sale a lot of homoeopathic medicines. All these medicines were dumped into one pile, and disposed of in one lot, there being various kinds of medicine in the mass. A boarding house keeper bought the mass and, some days after the purchase, the auctioneer asked her, 'what did you do with the Homoeopathic medicine, Mrs-?' She replied, 'I thought I could use it, and it was cheap, and so I crushed it under the roller and then filled my sugar bowls with them. The boarders seemed to like it, and especially when powdered over pies'. ${ }^{58}$

Physicians advocating 'orthodoxy' further suspected the homoeopaths of clandestinely prescribing allopathic medicines. As Robson noted in his pamphlet:

The homoeopathic medicine has no power for good or evil. The homoeopathic practitioner seeming to do something, in reality does nothing to delay the course of the disease, unless as is not infrequently the case, he surreptitiously employs allopathic treatment. ${ }^{59}$

Physicians writing in favour of homoeopathy put forth a resolute defence of the scientific merit of their infinitesimal drugs. In response to the various attacks, the

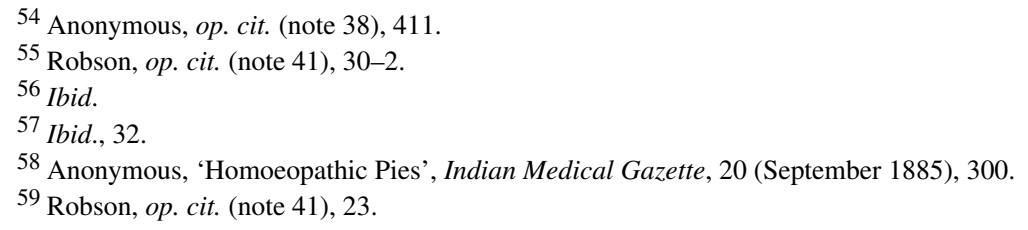


rationale of minute dose was elaborately discussed in a number of journals. These physicians invoked a series of analogies to justify their minute doses. Paradoxically, the analogies were always based on the established truths of what they dismissed as 'orthodox'/'allopathic' medicine. Physician Biharilal Bhaduri wrote in the article 'Homoeopathyr Olpo Matray Karjokarita [Usefulness of Small Doses in Homoeopathy]' in Chikitsha Sammilani:

Nobody knows till now what malaria is, but everybody knows what immense destruction is caused by this invisible substance. In vaccination too, the medicine used is minute in quantity. Even the recent powerful microscopes cannot determine how much of small pox seed they contain. In this and in many other ways it may be shown how great tasks are accomplished by smallest particles. ${ }^{60}$

Similarly, in the article 'Homoeopathic Oushadh er Karjokarita [The Efficacy of Homoeopathic Drugs]' published in the ninth volume of the same journal, Dr Pratap Chandra Majumdar argued that:

[E]ven allopaths believe in certain minute atoms as the cause of diseases. They hold that bacterium, bacillus and other organisms trigger off diseases like cholera, small pox etc. All of these are minute in size. Therefore, it is odd that they do not see logic in the fact that smallest particles of medicines may also heal. ${ }^{61}$

Physicians writing against homoeopathy completely rejected the claims of homoeopathic analogies. In myriad texts, they deeply engaged with the homoeopathic comparisons and dismantled them with counter critiques. Dr Robson thus argued:

With regard to the analogy attempted to [be] established by the homoeopaths between their infinitesimal doses and the action of miasmata, I remark that it does not follow that, because miasmata entering the system by the lungs exert a powerful influence on the animal economy, that homoeopathic medicines, which are usually taken into the stomach and digested, would have a corresponding effect. ... Again, the venom of a serpent may be swallowed with impunity, but if introduced beneath the skin, a very small quantity will prove fatal....62

It is interesting to note, however, that, in their sincere efforts to establish the scientific merit of homoeopathic doses, homoeopaths indirectly sought legitimacy from what they dismissed, ie. the tenets of 'orthodox' medicine. In the process, they often ended up confirming the validity of so-called 'allopathic' ideas and discoveries. It was through such mutual engagement, endorsement and opposition of ideas that the contours and scope of the two medical systems were delineated.

\section{Contested Histories, Rival Traditions}

Antiquity of the two medical doctrines was an arena of further contestation. Existing historiography has noted that, with the emergence of a nationalist consciousness, history as an important and authentic mode of accessing the past. ${ }^{63}$ By the late nineteenthcentury, history was widely regarded as a powerful legitimising tool - one that the colonial masters had taught the natives. ${ }^{64}$ Small wonder then that a range of authors promised to

\footnotetext{
${ }^{60}$ Biharilal Bhaduri, 'Homoeopathy'r Olpo Matray Karjokarita', Chikitsha Sammilani, 3 (1886), 37-9.

61 Pratap Chandra Majumdar, 'Homoeopathic Oushudh er Kaarjokarita', Chikitsha Sammilani, 9 (1892), 340-2.

62 Robson, op. cit. (note 41), 21.

63 See Partha Chatterjee, 'Nation and its pasts', in The Nation and Its Fragments: Colonial and Postcolonial Histories (Princeton, NJ: Princeton University Press, 1993), 88-94.

${ }^{64}$ For a recent exposition of such an idea, see Prathama Banerjee, Politics of Time: 'Primitives' and History Writing in a Colonial Society (New Delhi: Oxford University Press, 2006). The work seeks to explore what it meant for the colonial modern subject to write and make history.
} 
narrate the 'history of homoeopathy' ${ }^{65}$ The antiquity of homoeopathy and its rich historic past comprised a topic of serious discussion for them. Unlike some of their European counterparts, in narrating homoeopathy's history the Bengali texts hardly ever focused on procuring the 'authentic' papers pertaining to Hahnemann. ${ }^{66}$

In Bengali journals and pamphlets, homoeopathy was shown to be as old as the Hippocratic corpus. Hippocrates himself was credited with the reputation of suggesting the homoeopathic law of similars for the first time. These publications firmly held that the homoeopathic law had fallen into disuse since the days of Galen. The homoeopaths argued that Galen popularised the idea of cure through contraries, which in time formed the backbone of western orthodox medicine. However, certain exceptional personalities down the ages upheld the importance of the other forgotten law: the law of similars.

In his conversion speech, Mahendralal Sircar, for instance, invoked past references to the principle of similars from preceding centuries. ${ }^{67}$ Late nineteenth-century Bengali tracts on homoeopathy, including many biographies of Hahnemann, devoted considerable space in delineating the antiquity of homoeopathic principles. One of the most wellarticulated discussions regarding the historical past of homoeopathy is the tract written by Mahendranath Raya in 1881 entitled Homoeopathy Abishkorta Samuel Hahnemann er Jiboni [The Biography of Hahnemann; the Discoverer of Homoeopathy]. ${ }^{68}$ In the second chapter of the book, titled 'Is Samuel Hahnemann indebted to someone in the discovery of homoeopathy? - A historical account', the author discussed the antiquity of homoeopathy at length. The author argued that homoeopathy in reality was as old as allopathy itself, for both were conceived by Hippocrates in 460 BC. This biographer of Hahnemann in Bengali propounded that it was Galen who in 103 BC made popular the idea of cure by opposites that was subsequently taken up by other physicians so that it became the dominant idea in medicine. Nevertheless, he stressed that the other trend, of "cure by likes', also survived, practiced by stray physicians of every century. Mahendranath Ray actually made a list of such physicians - Valentine in the fourteenth century, Paracelsus in the fifteenth century, etc. In their attempt to gain legitimacy, the homoeopaths thus ended up enumerating the historical trajectory of orthodox medicine as well. A particular historical contour of western medicine was thus being constructed through the writings of late nineteenth-century homoeopathic physicians in Bengali print.

At the same time, a paradoxical claim also characterised the writings of late nineteenthcentury homoeopaths. Trying to establish their own legitimacy, homoeopaths on the one hand stated the long historical genealogy of homoeopathy. On the other hand, homoeopathy was highlighted as the latest discovery in medicine. Hahnemann's discovery of the law of similars in 1790 was projected as an extraordinary autonomous achievement. Successive texts in Bengali reiterated that Hahnemann was unaware of the knowledge of the already existing law of similars. To the homoeopaths, Hahnemann's discovery was a renewed breakthrough in the realm of therapeutics at the turn of the nineteenth century.

65 See, for instance, J.N. Majumdar, 'History of Homoeopathy', Indian Homoeopathic Review, 10, 8 (August 1911), 225-30; S.C. Ghosh, History of Homoeopathy in India (Calcutta: International Institute of History of Homoeopathy, 1997 [1906]).

${ }^{66}$ See, for instance, R.E. Dudgeon, History of Homoeopathy: Its Origins, Its Conflicts with an Appendix on the Present State of University Medicine (London: Gould, 1885), i-v; see also J.H. Clarke and F.L.Wheeler (eds), Samuel Hahnemann, His life and Work Based on Recently Discovered State Papers, Documents, Letters etc (London: Homoeopathic Publishing Company, 1922), ix-xvi.

67 Sircar, op. cit. (note 37), 22.

68 Mahendralal Raya, Homoeopathy Abishkorta Mahopadhyay Samuel Hahnemann er Jiboni (Taligunj: KasiKharda Press, 1881), 31-6. 
Homoeopathy, it was claimed, opened up a new direction towards the making of a truly scientific medicine. Referring to Hahnemann's great insights, Mahendralal Sircar argued in the article 'Hahnemann: His Place in the History of Medicine':

Judged by its magnitude and importance, his discovery has been the most glorious and beneficent that has yet been made, and his name will stand as the greatest in medicine. Whatever developments the science will attain in future, they will all be in the direction he has pointed out... the minute dose of the homoeopathically selected remedy will remain the main pillars upon which the science and art of healing by drugs will rest. ${ }^{69}$

Physicians favouring 'allopathy' vociferously contested the historical claims of homoeopathy. The author of an article in the journal Anubikshan [Microscope] argued allopathy to be the 'oldest and the strongest school' ${ }^{70} \mathrm{He}$ argued that 'every country has its own form of Allopathy, and that Unani or Hakimi prevalent in parts of Asia and Africa is but a form of Allopathy'. ${ }^{71}$ The author talked about the presence of Hindu medicine in ancient India and that of Hakimi in the Muslim period and acknowledged the late entry of allopathy, the oldest form of medicine, in India. Homoeopathy according to him was a 'new, an upstart branch of medicine'. ${ }^{72}$ In the introduction of the very first volume of the journal Chikitshak O Samalochak [Physician and the Critic] in 1895, editor Satyakrishna Ray noted: 'it (Homoeopathy) has been invented in the 19th century and has gained prominence only in these last $30 / 40$ years' ${ }^{73}$ Both the journals attributed the origin of the school to the genius of Hahnemann, who, as the editor of Anubikshan wrote, 'lived only in the last quarter of the 18th century'. ${ }^{74}$ 'The system is so new', the editor argued in Chikitshak $O$ Samalochak, 'that though it is becoming quite entrenched in America nowadays, it is not even recognised by the University of Calcutta!'. 75

In their attempt to chart out a continuous historical trajectory for homoeopathy, nineteenth-century physicians made strong futuristic assumptions too. Leopold Salzer, the Viennese homoeopathic practitioner in Calcutta, wrote an interesting article entitled 'Reflections of a Future Historian of Medicine', in the Calcutta Journal of Medicine in $1869 .^{76}$ In an exciting conjectural approach the article dealt with what, 200 years after him in 2069, might be the thoughts of a historian of medicine, confidently assuming that by 2069 homoeopathy would be the dominant medical system in vogue.

\section{Norms of 'A Scientific Debate'}

The preceding sections have mapped the medical debates crystallising notions of 'allopathy' and 'homoeopathy' in Bengali print. This article argues that the vibrant print market in Bengal was a crucial factor in forging these identities. Although the discussions rarely took the form of formal organised debates, these writings by contending physicians were mostly in conversation with one other. In their attempt to establish the superior 'scientific' merit of their therapeutics, homoeopathic physicians expressed

\footnotetext{
${ }^{69}$ Mahendralal Sircar, 'Hahnemann; His Place in the History of Medicine', Calcutta Journal of Medicine, 10, 5 (May 1882), 181.

${ }^{70}$ Anonymous, 'Chikitsha', Anubikshan, 1 (1875), 5.

71 Ibid.

72 Ibid.

73 Satyakrishna Ray, 'Introduction', Chikitshak O Samalochak, 1 (1895), 5.

74 Anonymous, op. cit. (note 70), 6.

75 Ray, op. cit. (note 73), 6.

${ }^{76}$ Leopold Salzer, 'Reflections of a Future Historian of Medicine', Calcutta Journal of Medicine, 2 (March 1869), 104-15.
} 
themselves in a range of publications including journal articles, pamphlets, manuals and books. Through their writings, they repeatedly attacked those whom they considered 'orthodox', 'old school' or 'allopath'. Trying to establish what homoeopathy was not, these physicians sketched the definite contour of a historical tradition named 'allopathy'. Interestingly, these allegations were hardly ever monologues. In response to the advocates of homoeopathy, many physicians strongly asserted their identities as practitioners of 'allopathy' in print. They in their turn criticised various aspects of what they referred to as the homoeopathic system. As this article demonstrates, very specific connotations of the terms 'allopathy' and 'homoeopathy' emerged through these correspondences in the vernacular print market. By the end of the nineteenth century, 'allopathy' almost completely replaced the previously prevalent terms such as 'official medicine', 'state medicine', 'rational medicine', 'European medicine' and others deployed to refer to the medical ideas disseminated by the British colonial state. In the world of medical print in Bengal, as also in official bureaucratic discourses, 'allopathy' became the most widely circulating name of a 'western orthodox medical tradition' dating back to the days of Hippocrates. ${ }^{77}$

Studied together, these discussions as recorded in a myriad of scattered publications of the period hint at the anatomy of a long-standing debate concerning scientific therapeutics. Moreover, as this section would illustrate, the physicians themselves often labelled their correspondence as debates. Indeed, the act of debating was highlighted as an important scientific practice in itself. The discussants were frequently emphatic about the expected ethics and norms of 'scientific debates'. Hence, along with the content of such debates, there were elaborate remarks and commentaries on their form.

Physicians promoting homoeopathy held the orthodox physicians guilty of adopting unacceptable expressions and gestures in their polemical opposition to the homoeopaths. Such objectionable language, homoeopathic texts lamented, flouted the exalted norms of respectable scientific debate established in and inherited from the west. Homoeopaths thus appeared to assert a pristine moral code for conducting and narrating western science in the vernacular. In so doing, homoeopathic writers upheld their own works as benchmarks of credible, respectable and effective writing of science in Bengali. They were extremely careful about what could and could not be included in scientific discussions concerning therapeutics. Certain idealised norms of scientific discussion were central to their writings. In his introduction to the fourth manual in Berigny and Company's Bengali Homoeopathic Series, Harikrishna Mallika, for instance, was hesitant in introducing a discussion involving venereal diseases. He argued that a discussion of those diseases invariably entailed the use of vulgar or 'oshlil' words and phrases. He considered it inappropriate to use such words in serious scientific discussions on treatment. He feared that discussions involving such unchaste words could be revolting to the 'taste' of the respectable men for whom they were meant. ${ }^{78}$ Questions of 'morality' and 'taste' remained integral to the assumed codes of scientific debate.

\footnotetext{
77 See, for instance, S. Khan, 'Systems of Medicine and Nationalist Discourse in India: Towards 'New Horizons' in Medical Anthropology and History', Social Science and Medicine, 62 (2006), 2786-97. The article discusses the nationalist debates on health policies to be adopted in India based on the Proceedings of the United Province Legislative Assembly in the late 1930s. It is important to note that the bureaucratic debates widely referred to a dominant form of western medicine in India known as allopathy.

${ }^{78}$ Harikrishna Mallika, 'Introduction', in Berigny and Company's Bengali Homeopathic Series No. IV: Sadrisa Byabastha Chikitsha Dipika (Calcutta: Berigny and Company, 1870), page number not cited.
} 
The style and demeanour of registering disagreements and arguments on scientific issues were often discussed. In a text carefully compiled by homoeopath Mahendralal Sircar, the Hindu Patriot, for instance, was quoted to have condemned the aggressive tone of the orthodox physicians reminding them that they ought to remember that they 'not only belong to a profession but that they teach a science'. ${ }^{79}$ It was considered unacceptable the way in which 'he [Mahendralal Sircar] was denounced as a Homoeopath, the grossest personal attacks was allowed to be made on him..., 80

Commentaries on medical discussions thus hinted also at an emerging ethic of scientific debates. Such commentaries made a fundamental distinction between scientific critique or 'samalochana' and outright quarrel or 'jhogra'. An anonymous homoeopathic reviewer in Chikithsha Sammilani thus observed:

[I]nformed debates involve a lot of reading and learning. In place of debating uneducated men simply shout. It is very difficult to critique, very easy to quarrel. It is painful to see how educated men quarrel in the name of debating and critiquing. ${ }^{81}$

The editors of the journal Chikitsha Sammilani regularly commented upon the language used in medical discussions. For instance, they expressed their disgust about the language and form of the anonymous homoeopathic reviewer quoted above. The editors pointed out that unrestrained and provoking, his style lacked solemnity. To them it was completely inappropriate for serious scientific discussions. ${ }^{82}$

\section{Conclusion}

This article has mapped the constitution of ideas concerning contending medical traditions in Bengali print since the mid nineteenth century. Long correspondence and interactions between physicians claiming to practice diverse varieties of therapy facilitated the process. Homoeopathic self-assertion to establish its scientific merit did not take place on its own. It deeply engaged with the rationale and features of what it labelled as orthodox medicine. Physicians associated with the state medical establishment in various capacities frequently retaliated, asserting their identities as 'allopathic' practitioners. The features and scope of the two medical systems were clearly delineated in the process. The self-projection of Bengali homoeopaths in late nineteenth-century Bengal thus helped define their other: the allopaths. This article has emphasised the role of the supposed 'fringe', ie. homoeopathy, in identifying and organising the 'orthodoxy' of the time. In so doing, it has shown how the shared market for medicine and print provided a crucial platform where such binary identities as 'homoeopaths' and 'allopaths' were simultaneously constituted and reinforced. As noted in the introduction, this trend was most vibrant in the late nineteenthcentury medical print in the decades between the 1860s and the 1890s. At the turn of the century with the increasing entrenchment of ideas concerning bacteriology and the passing of the Medical Registration Acts $^{83}$ that in effect denounced homoeopathy, the

\footnotetext{
${ }^{79}$ Mahendralal Sircar, On the Supposed Uncertainty in Medical Science and on the Relation between Diseases and their Remedial Agents, 2nd edn (Calcutta: Anglo Sanskrit Press, 1903), 67-8.

${ }^{80}$ Ibid., 67-8.

81 Anonymous, 'Letter to the Editor', Chikitsha Sammilani, 5 (1888), 98.

82 'Editors Comments', Chikitsha Sammilani, 5 (1888), 113.

83 The Medical Registration Acts were being passed in various provinces one after the other. The Bengal Medical Act, passed in April 1914, sought to define the 'registrable qualifications' of physicians in a way that in effect denounced the practice of homoeopathy in Bengal. A National Act titled the Indian Medical (Bogus Degree) Bill was passed in 1915 with much the same effect. For a discussion of the National Act see R. Berger, 'Ayurveda
} 
nature of interaction between the two groups of physicians in print stood considerably altered. The sustained correspondence and debates were distinctly on the decline. On the rare occasions where mostly the homoeopaths initiated such discussions, the terms of debates were pitched at different registers than in the nineteenth century. The twentiethcentury contentions primarily revolved around the disease causing potentials of germs. ${ }^{84}$

However, it is important to note that voices of dissent against the adverse late nineteenthcentury debates were not infrequent. A number of contemporary authors emphasised the futility of such a clash of ideas. It was frequently pointed out that the patients continued to suffer, as the physicians debated the scientific features, principles and efficacy of their therapy. A simultaneous sense of rage and disgust against the debates can be noticed in the pages of those very journals. Jadunath Gangopadhyay's 'Chikitsha Shastrer Porinaam [Consequence of Medical Systems]' is a representative piece published in the journal Chikitsha Sammilani in 1889. The author expressed his deep-seated anxiety at the uselessness of modern scientific medicine itself. ${ }^{85}$ He urged the readers and patients to be aware of the futility of the unceasing battle of ideas between the allopaths and the homoeopaths. ${ }^{86}$ Commentators such as Gangopadhyay repeatedly alarmed their readers by referring to the perceived limitations of modern western medicine, be it homoeopathy or allopathy, in the face of various diseases and epidemics that plagued the people.

and the making of the urban middle class in north India, 1900-1945', in D. Wujastyk and F. Smith (eds), Modern and Global Ayurveda: Pluralisms and Paradigms (State University of New York Press, 2008), 103-4.

${ }^{84}$ See, for instance, K.K. Bhattacharya, 'Homoeopathy Bonam Allopathy O Onyanyo Chikitsha Pronali', Hahnemann, 23, 6 (1940), 345.

85 Jadunath Gangopadhyay, 'Chikitsha Shastrer Porinaam', Chikitsha Sammilani, 6 (1889), 101-12.

86 Ibid. 